\title{
Pueblo, política y comunicación: la recepción del discurso del presidente Rafael Correa
}

Mauro Cerbino

Marcia Maluf

Isabel Ramos ${ }^{1}$

\section{Introducción ${ }^{2}$}

Este artículo tiene origen en un estudio que evaluó la opinión de la población del Ecuador, tomando en cuenta los diversos sectores socioeconómicos y geográficos del país, acerca del gobierno del presidente Rafael Correa y del conflicto que sostiene con los medios de comunicación desde el inicio de su gestión en 2007. En aquella investigación surgió una serie de preguntas: ¿Cuáles son las ideas e imágenes con las que los ciudadanos identifican al presidente Correa y a su gobierno? ¿Cómo re-significan los ciudadanos las ideas, acciones y propuestas del Presidente?, y ¿qué nuevas representaciones y efectos producen sobre la política, la convivencia social, los actores políticos, el país? Estos interrogantes nos ubican de manera predominante en el campo de los efectos de la comunicación política e indirectamente en el papel de los medios de comunicación masiva en el campo político.

Para contextualizar el análisis, evaluamos la comunicación política que el gobierno de Correa ha desarrollado desde su llegada al poder. Analizaremos las características del programa Enlaces Ciudadanos ${ }^{3}$, que el presidente transmite al país cada sábado con una duración, en promedio, de cuatro horas. Los argumentos con que el presidente construye su propia imagen, la de los sectores de oposición, y la de los medios de comunicación, entre otros actores políticos, resultan claves para comprender el significado con las que los ciudadanos ecuatorianos expresan la aprobación a su gobierno.

Nuestra investigación se ubica en un momento histórico particularmente significativo del gobierno de Rafael Correa: la sublevación de una parte de la policía

\footnotetext{
1 Los escritores aparecen por orden alfabético de apellidos.

2 Este artículo forma parte de una investigación más amplia sobre la comunicación política del gobierno ecuatoriano. Los resultados parciales de este trabajo se expusieron en congresos y eventos académicos nacionales e internacionales. Además, se hicieron algunas publicaciones al respecto. El presente artículo pretende abordar la reflexión de un aspecto poco visitado en la investigación de la comunicación política: la recepción, entendida como proceso activo de construcción de sentidos por parte de los públicos. Los autores desean expresar su gratitud a José Morán y Gustavo Fuchs, estudiantes becarios de la maestría en comunicación de Flacso-Ecuador por su valiosa colaboración en la recolección y transcripción de las informaciones aquí analizadas.

3 El Enlace Ciudadano es un programa televisivo y radiofónico producido por la Secretaría Nacional de Comunicación en el cual el Presidente rinde cuentas de su gestión. Es transmitido por un conjunto de radioemisoras y canales de televisión a lo largo del país, que se unen, de modo voluntario, a la señal de la Radio y la Televisión Públicas.
} 
nacional y el intento de subvertir el orden a partir del secuestro durante varias horas del Presidente, ocurrido el 30 de septiembre de 2010. Consideramos que este hecho representa un primer punto de inflexión y de crisis en un contexto político que desde 2007 (año de toma de posesión) se había mostrado extremadamente favorable al gobierno de Correa. A partir de este momento, el Presidente se vio obligado a reorientar la legitimidad de su acción ante la ciudadanía, en el ámbito de una nueva reconfiguración de las fuerzas políticas, lanzando ocho meses más tarde la iniciativa de una consulta popular con diez preguntas sobre varios temas de interés nacional. Cabe también señalar que Enlaces Ciudadanos constituye la plataforma más eficaz de comunicación política que utiliza el gobierno y que incluye cadenas nacionales, así como rendición de cuentas semanales. Dicha eficacia se debe fundamentalmente al carácter ritual que se despliega en el tono y uso de expresiones presidenciales que remiten a una suerte de liturgia, cuyo efecto imaginario es ampliar la participación popular por medio de la identificación con el líder, algo que es particularmente relevante analizar en el artículo que se presenta a continuación.

Ernesto Laclau, siguiendo a Freud, ha utilizado este concepto para explicar un modo de lazo social que se produce entre los miembros de un grupo "a raíz de cualquier nueva percepción de una cualidad común compartida con alguna otra persona que no es objeto de las pulsiones sexuales" (Freud, en Laclau, 2005, p. 78). Esta cualidad común es el lazo con el líder que se inviste de amor, que puede adoptar varias formas y su rasgo común es la idealización del objeto. Agrega Laclau para explicar la importancia de este vínculo amoroso en la política que

el líder sólo será aceptado si presenta, de un modo particularmente marcado, los rasgos que comparte con aquellos que se supone que debe liderar. En otras palabras: los liderados son, en gran medida, in pari materia con el líder - es decir, este último se vuelve primus inter pares (Laclau, 2005, p. 83).

El estudio deja de lado posiciones moralizantes acerca del carácter negativo que algunos análisis atribuyen a los liderazgos denominados peyorativamente "populistas" (Novaro, 1996; Paramio, 2006; De la Torre, 2013). Entendemos que estos autores, al poner el acento en el clientelismo y en la manipulación como claves explicativas de la popularidad de un gobernante, subestiman al ciudadano común, y sus opiniones políticas, subrayando el carácter irracional de las mismas. De hecho, son implícitas a esas perspectivas algunas dimensiones fundamentales con las que los críticos del populismo conciben la política, la democracia y el gobierno. En primer lugar, existe un modo de interpretar el conflicto o el antagonismo no como constitutivos de la sociedad política, sino en términos de la alternancia de gobierno en un marco de institucionalidad cuyo vocabulario político se vuelve inmutable. Lo que implica desconocer y desvalorizar las rupturas contra-hegemónicas que, según una concepción discursiva y contingente de la política - que es la que adoptamos aquí - pueden producirse con base a disputas por el sentido común como elemento de agregación en la esfera de lo político. El carácter 
contingente significa que no es posible sostener la idea de pueblo como una categoría cuyo contenido ideológico y político sea definido a priori, como pretenden hacer los detractores del populismo. En segundo lugar, persiste la convicción en torno a una definición procedimental de la democracia, cuya medida de calidad es reconducida hacia el rigor de métodos establecidos en el seno de las élites técnicas - expertas e intelectuales - que anteponen el imperio de las leyes a los empujes constituyentes que podrían provenir de los sectores populares y plebeyos. De ahí que sin temor a equivocarse se puede decir que lo contrario del populismo no es la democracia (Bartra, 2008; Sánchez Parga, 2009) sino la tecnocracia.

El artículo se propone mostrar los diversos razonamientos e interpretaciones de los ciudadanos que son al mismo tiempo destinatarios y receptores activos de un discurso político que se reconfigura a partir de la elaboración de un nuevo vocabulario contencioso. En ese sentido, el presente artículo constituye no solamente un ejercicio de reconstrucción del significado producido por sujetos en general no escuchados sino, también, una práctica ciudadana de diálogo político con interlocutores diversos que se muestra claramente en el uso de nuevos sustantivos de signo político.

\section{Metodología}

Por todo lo dicho, nos propusimos pensar la comunicación política desde dos dimensiones que tienen vínculos complejos y necesarios. Por una parte, la dimensión de los sentidos plasmados en el discurso político y, por la otra, la de la interpretación que realizan los ciudadanos receptores del mensaje. El análisis discursivo nos permitió describir los contenidos, las formas expresivas y las interpelaciones que se movilizan en el Enlace ciudadano. Asimismo, recurrimos a la técnica de grupos de discusión (focus groups) con la finalidad de reconocer las narrativas y las experiencias individuales y colectivas en la recepción de esta plataforma de comunicación política.

Para nuestro análisis fueron seleccionadas, como corpus, los discursos que el presidente Correa dirigió a la población entre los meses de enero y junio de 2011 , periodo en que se producen dos acontecimientos políticos relevantes: 1) la consulta popular realizada el 7 de mayo de 2011, y que puso a consideración de los electores diez preguntas sobre reformas legales y de políticas públicas, y 2) el juicio al periodista Emilio Palacio y a directivos del diario El Universo debido a la acusación de este periodista al Presidente de haber cometido un crimen contra la humanidad, que fue denunciada como injuria por Correa (Palacio, 2011). Dicho periodo coincide con uno de los momentos más sobresalientes del conflicto del gobierno con los sectores tradicionales de la política, la oposición, y en particular, con los medios de comunicación privados, los cuales son identificados en el discurso presidencial como los principales adversarios en la campaña que se opuso al plebiscito. En total, se han analizado trece Enlaces Ciudadanos.

A partir de la decisión teórico-metodológica en torno a la articulación entre comunicación política y análisis de discursos - lo que implica que se entrecruzan categorías 
PUEBLO, POLÍTICA Y COMUNICACIÓN: LA RECEPCIÓN DEL DISCURSO DEL PRESIDENTE RAFAEL CORREA

como legitimidad, hegemonía y espacio político, y se remite a la enunciación, al dialogismo y a las formas diversas de manifestación del sentido - el otro componente de este artículo ha sido el análisis de la recepción del discurso del presidente Correa por parte de los ciudadanos. Como indica Orozco Gómez, estos estudios enfatizan en la producción de sentido como centro de su interés:

Los ER [estudios de recepción] siguen siendo una opción para entender no sólo a los sujetos sociales contemporáneos en las interacciones varias que entablan con los medios y tecnologías de información, sino también mucho de los procesos socioculturales, políticos y económicos mayores de los cuales participan (Orozco Gómez, 2003, p. 7).

Para lograrlo, realizamos convocatorias públicas para participar en grupos de discusión, en los cuales procuramos reconocer las representaciones, modos de clasificación y argumentos de los participantes acerca del discurso presidencial. Nos propusimos dialogar con personas adultas de al menos dos segmentos socioculturales bien diferenciados, en las tres ciudades más grandes del país: Quito, Guayaquil y Cuenca. Estas ciudades no solo han sido seleccionadas por su tamaño poblacional, sino también porque representan realidades muy distintas y por lo tanto significativas desde el punto de vista de su composición social, étnica y cultural. En el caso de Quito y Cuenca son más numerosos los sectores identificados con la clase media, mientras que en Guayaquil se observa la presencia de un gran sector popular, con lo cual se pueden rescatar diferencias relevantes, en términos de influencia política y opinión pública, en cada una de las ciudades.

Por tanto, el rasgo de afinidad seleccionado para la integración de los grupos de discusión fue el socioeconómico, al cual, sin embargo, se agregaron otras características previamente definidas para la selección de los componentes de los grupos de discusión. Estas fueron: género, edad, nivel educativo y ocupación. Cada uno de los grupos de discusión se integró con un número de personas de 6 a 8, por un total de 41 participantes, cuyos perfiles estaban distribuidos según los porcentajes reportados a continuación: mujeres (40\%); hombres (60\%); jóvenes (18-29 años) (30\%); adultos (30-55 años) (70\%); con educación básica (30\%); con educación media (40\%); con educación superior $(30 \%)$; empresarios (15\%); trabajadores calificados $(45 \%)$; trabajadores no calificados (40\%).

Las citas textuales (verbatim) que se localizan a lo largo del documento identifican el participante, su perfil, el grupo y la ciudad en la que el grupo de discusión fue realizado. No obstante, en el presente texto se reportan solo algunos extractos del total de intervenciones realizadas por los participantes, las mismas que surgieron en la dinámica de la discusión y que fueron de mayor relevancia y significado para el objeto de estudio de este artículo. 
Los ejes temáticos que guiaron la formulación de las preguntas en las discusiones grupales fueron los siguientes:

\begin{tabular}{|c|c|}
\hline Eje temático & Preguntas \\
\hline Politización social & $\begin{array}{l}\text { ¿A qué sectores respalda/defiende el presidente? } \\
\text { ¿Tiene usted mayor o menor interés por la } \\
\text { política que años atrás con otros gobiernos? } \\
\text { ¿Considera que el país está más o menos } \\
\text { politizado que antes? }\end{array}$ \\
\hline Comunicación política & $\begin{array}{l}\text { ¿Sobre qué cuestiones el gobierno informa más? } \\
\text { ¿Qué piensa de... (Enlace, cadena, spot, cuña, } \\
\text { según haya sido nombrado por el grupo)? } \\
\text { ¿Qué le parecen los Enlaces Ciudadanos? }\end{array}$ \\
\hline Relación con los medios privados & $\begin{array}{l}\text { ¿Piensan ustedes que el gobierno se enfrenta } \\
\text { con los medios de comunicación? } \\
\text { ¿Qué piensan de la información que } \\
\text { proporcionan los medios sobre política? } \\
\text { ¿Piensan que es necesario regular a los medios? } \\
\text { ¿Qué significa para ustedes la libertad de } \\
\text { expresión? }\end{array}$ \\
\hline Participación social y política & $\begin{array}{l}\text { ¿Sienten que hay participación de las personas } \\
\text { en la vida política del país? } \\
\text { ¿Ha habido suficientes espacios de participación } \\
\text { para la ciudadanía? } \\
\text { ¿Sienten que las decisiones que se toman son } \\
\text { para el pueblo? }\end{array}$ \\
\hline
\end{tabular}

\section{El discurso político de Rafael Correa: entre la exaltación del pueblo y el combate a los medios}

Enlace ciudadano es un programa de radio y televisión que, en sus inicios, en 2007, fue planteado como un espacio de rendición de cuentas de la labor realizada por el Presidente durante la semana. Poco a poco se fueron incorporando contenidos relacionados con la historia del país y con la promoción del mismo como destino turístico, información detallada sobre el desarrollo de obras y políticas públicas y, además, un espacio especialmente dedicado a confrontarse con los medios de comunicación (Chavero y Cerbino, 2015, p. 7). El programa no cuenta con una división en bloques temáticos dado que el hilo conductor es la actividad diaria del mandatario, cuya información se complementa con una serie de productos audiovisuales, como reportajes, documentales, presentaciones en power point, fotografías e, incluso, planos de las obras públicas realizadas o proyectadas.

Desde un escenario rodeado de banderas nacionales y con una pantalla gigante como fondo, Correa se sienta a una mesa decorada con un simple mantel blanco y, micrófono en mano, se dirige al público presente, que lo acompaña desde una platea 
especialmente montada al aire libre, en una cancha, plaza o espacio público. Un elemento importante de la puesta en escena de Enlace ciudadano es el ingreso de un Presidente sonriente, que atraviesa el improvisado pasillo central, recibiendo saludos y tomándose fotografías con los asistentes. Es importante tener en cuenta que, durante todo el programa, el Presidente habla solo. Únicamente cede la palabra por unos minutos para que algún funcionario proporcione detalles o responda a sus preguntas. Los ciudadanos no están invitados a preguntar ni a intervenir.

Nuestro análisis de los Enlaces Ciudadanos nos permite pensar que, a través de sus discursos, el presidente Correa busca configurar una nueva hegemonía, un nuevo régimen de verdad cuyos elementos constitutivos son la exaltación del pueblo, la construcción de un ethos personal y político identificado con la integridad y la defensa del ciudadano común frente a los abusos de las élites tradicionales, y la disputa permanente con los medios de comunicación privados, que el Presidente identifica con dichas élites. Este discurso se contrapone y se confronta con formas otrora aceptadas como legítimas en Ecuador, las promovidas por los medios de comunicación comerciales. Por esta razón, la confrontación se plasma en énfasis y repeticiones, en slogans y mensajes publicitarios, formas expresivas en las cuales se manifiesta un antagonismo permanente. De este modo, Correa asume la función del intelectual orgánico, que, según Gramsci (2004), representa a las clases subalternas, en el papel de quien pone en evidencia la dominación de los sectores económicos, políticos e ideológicos, y su dirección hegemónica durante la etapa neoliberal. En este sentido, es posible afirmar que el discurso de Correa tiene un componente emancipatorio que puede funcionar como dispositivo de toma de conciencia para sí de las clases populares.

En los Enlaces Ciudadanos, Correa busca subrayar ante su audiencia la identificación del gobierno con el pueblo llano, para constituir claramente la oposición entre un nosotros y un ellos en términos de clase. Por lo mismo, su discurso puede interpretarse como un elemento sustancial de disputa por la hegemonía, la cual necesita de símbolos que aglutinen a los sectores populares, que los convoquen y promuevan su identificación (Laclau, 2005) y que, al mismo tiempo, produzcan diferenciaciones radicales con los sectores política y económicamente dominantes.

En el discurso del Presidente se combinan la razón y la pasión, siendo ambos elementos claves en la construcción de sus argumentos. Del estudio de nuestro corpus se desprende que, además de poseer fuertes componentes persuasivos, el discurso de Correa es portador de numerosos elementos explicativos. El análisis del discurso diferencia estas dos modalidades. Mientras que la persuasión es un modo de argumentación que pone de relieve aspectos emocionales del discurso con el fin de conmover al auditorio y lograr que éste comparta una opinión o idea sin apelar a criterios de autoridad (Charaudeau, 2009), la explicación intenta elucidar el por qué y el cómo de un fenómeno particular y supone una verdad que está por fuera del sujeto enunciador, que el oyente no conoce. Por este motivo, la explicación forma parte del discurso de la información y de la enseñanza (Verón, 1987). 
El presidente transmite conocimientos y produce enunciados valorativos sobre el país, las instituciones, y los actores políticos. Se trata de un discurso pedagógico particular, en el que predominan las emociones más que el afán de convencer a través del razonamiento. De este modo, el discurso presidencial busca generar lazos de identificación y empatía con amplios sectores de la población. En lugar de exhibir un saber ilustrado y de hablar desde la majestad del poder, Correa produce enunciados en los que se identifica con el pueblo, a través del uso recurrente de un lenguaje cercano al mundo popular, que se sirve del humor, de la ironía, y de un habla enérgica que transmite pasión e indignación ante las injusticias, los engaños y la manipulación de la que ha sido objeto históricamente el pueblo ecuatoriano:

Como nunca, la plata del IESS ${ }^{4}$ en beneficio de jubilados y afiliados, con los nuevos centros de atención, los nuevos hospitales, el Banco del IESS, crédito hipotecario, crédito quirografario. Ya no saben qué decir estos sinvergüenzas ¿verdad? Lo que pasa es que ya no se va a Estados Unidos, a sus patrones, para ganar menos del $1 \%$, sino que se queda esa plata aquí en beneficio del pueblo ecuatoriano, para financiar proyectos hidroeléctricos, proyectos petroleros, el banco del IESS. iY eso es lo que le duele a esta gente, que en vez de alma tiene un bolsillo! Y en el pecho no tienen la tricolor sino banderitas azules, blancas y rojas con estrellitas, ¿verdad? Eso es lo que le duele a esa gente. Pero esta es la clase de oposición que tenemos que enfrentar (Enlace 218, 23 abr. 2011).

En este sentido, el discurso de Correa surge y se alimenta de un contexto político en que uno de los actores más importantes, con gran influencia en la construcción de las representaciones sociales, la cultura y la política del Ecuador - el sector de los medios de comunicación - es identificado claramente como actor político, y, dadas sus actuaciones antagónicas frente al gobierno y sus vínculos con los sectores más poderosos del país, como el principal adversario del denominado gobierno de la Revolución Ciudadana. El discurso de Correa hace hincapié, primero, en el poder simbólico de los medios para influir de manera casi determinante en las formas de pensar y de actuar de los ciudadanos y, segundo, en su carácter manipulador y engañoso.

Desde una posición de amplia legitimidad política conseguida en las urnas, Correa confronta a sus oponentes y habla en nombre del pueblo, validando en todo momento su discurso como "verdadero":

pero si ustedes leen, "este Correa desgraciado de nuevo metió presos a dos pobres estudiantes que se opusieron a la consulta". iMentira! iTodo es mentira! Y eso seguirá todos los días. Conclusión: no hay que creerle nada a esa prensa corrupta (...). No le crean nada a esa prensa corrupta, empezando

\footnotetext{
${ }^{4}$ El Instituto Ecuatoriano de Seguridad Social es la entidad que administra las pensiones y jubilaciones y, además, ofrece asistencia sanitaria y financiera a los trabajadores.
} 
por El Universo ${ }^{5}$ [canción "Mienten, mienten, qué forma de mentir"] (Enlace 215, 2 abr. 2011).

Aquí quieren confundir libertad de expresión con la mentira. Total tolerancia con la libertad de expresión, cero tolerancias con la mentira. iAborrezcamos la mentira! Aquí nos quieren hacer pasar como virtud al que mejor sabe mentir. Así no se desarrollan las sociedades. Los que han vivido en el exterior saben que allá se aborrece la mentira. Entonces hay confianza, no necesito firmar contratos o nada, porque sabemos que no nos miente la gente. Aquí el más mentiroso es el más sabido (Enlace 218, 23 abr. 2011).

Recientemente se ha sostenido que el gobierno ecuatoriano compite con los medios para obtener el consenso de la opinión pública (Cerbino et al., 2014). En el proceso de esta competencia, el gobierno de Correa asume una doble posición. Por un lado, de "productor mediático", que utiliza los recursos tecnológicos propios de los medios de comunicación para generar mensajes en un marco programático de comunicación dirigido a la ciudadanía. Por otro lado, la de un "receptor", que responde críticamente a la información publicada, haciendo uso del juego, de la mímica y de la parodia para desacreditar a los medios y dirigir hacia ellos una demanda ética y política de que asuman responsabilidades y ejerciten la veracidad y la objetividad en la información que transmiten. Proponemos denominar a esta posición la del "gran receptor".

Decimos, por ello, que Correa se involucra como productor y receptor en un juego semántico y semiótico, en el que, Enlace tras Enlace, deja en claro de qué lado se ha ubicado el poder tradicionalmente ejercido en la producción de representaciones sociales, y en la construcción de adhesiones y antagonismos. Al mismo tiempo, sienta las bases para la generación de nuevos lenguajes y formas de transmitir mensajes en la comunicación política.

El uso de la ironía constituye, explícitamente, un recurso estratégico que a la vez que sirve para combatir al oponente, lo ridiculiza (Romano, 2001), al tiempo que genera un efecto de ethos de carácter y una imagen de ingenio e inteligencia en el enunciador, así como un efecto de pathos o de emoción en los destinatarios. Haciendo uso de figuras y denominaciones que han cobrado popularidad, el presidente incluye y excluye, como en el siguiente fragmento, en que busca crear un efecto de humor:

A todos esos hermanos, representantes de pueblos ancestrales, el compromiso de seguir luchando por sus derechos, pero en forma inteligente, sin odios, sin violencia. Uniendo el hombro para sacar adelante este Ecuador plurinacional, multicultural, que significa que existen pueblos ancestrales, indígenas, pero también existen pueblos afros, pueblos montubios, los cholos,

${ }^{5}$ Se trata de un diario de gran circulación en todo el país. 
y los mestizos, y los blancos. Los coloraditos ${ }^{6}$, los pelucones ${ }^{7}$, también son parte de este país, el problema es cuando se quieren adueñar de este país, pero yo soy presidente también de los pelucones (Enlace 208, 12 feb. 2011).

Mientras incluye en el discurso a los sectores con más poder económico, Correa destaca su condición de clase, buscando provocar o reafirmar una contraidentificación de su audiencia con estos poderes tradicionales. El Presidente intenta contrarrestar la acción de los medios, y al mismo tiempo, servirse de ella. Se hace patente el hecho de que, así como los medios se expresan en la esfera pública como actores políticos más que como informantes - algo de lo cual son reiteradamente acusados por Correa - él mismo parece forjarse como un actor mediático reconocido ante la ciudadanía. Esta suerte de superposición de funciones comunicativas hace del conflicto con los medios una confrontación permanente cuyas principales batallas se producen en el campo mediático.

Una estrategia relevante de Correa es haber puesto al descubierto el interés económico de los medios masivos. Los medios, y sus organizaciones nacionales e internacionales, "son empresas", gremios y corporaciones, de carácter privado, que producen como cualquier empresario - "en vez de papas, información" (Enlace 217, 16 abr. 2011):

Pero cuando llegamos al gobierno, El Universo era una compañía - no es sociedad anónima, es C.A, compañía anónima creo - propiedad de [una] empresa fantasma en Isla Caimán. Este negocio, porque es un negocio, una empresa privada con fines de lucro, propiedad de empresas fantasmas en paraísos fiscales. iIsla Caimán es la que nos da las noticias! ¿Por qué tenemos que creer en esta gente? ¿Por qué estos van a estar por encima del bien y el mal si son empresarios como cualquier otro, que buscan el fin de lucro y, si para defender su negocio tienen que mentir, lo van a hacer? Por eso se necesita la consulta popular, compañeros, para decir basta a tantos abusos (Enlace 217, 16 abr. 2011).

Por otra parte, el discurso de Correa está "desmediatizando" el uso de algunas nociones y construcciones, lo que constituye un importante cambio simbólico en el contexto analizado. Una de estas nociones es la de opinión pública, que en palabras de Correa no es la que se produce por la mediación de la prensa, la radio y la televisión, sino la que se encuentra en la plaza, es decir, en el pueblo; la que existe como un efecto de la interpelación política del gobierno, y no de los medios: "Aquí está la verdadera opinión pública, la voz popular. Nos quieren robar el derecho de expresarnos en las urnas" (Enlace 206, 29 ene. 2011).

Es prematuro afirmar que, por la vía de esta confrontación con los medios de titularidad privada, se estaría avanzando en la desmediatización de la comunicación

\footnotetext{
${ }^{6}$ Personas de piel clara y de cabello rubio.

7 Denominaciones ampliamente usadas por los sectores populares, especialmente de la costa ecuatoriana, para aludir a los poderosos y adinerados.
} 
PUEBLO, POLÍTICA Y COMUNICACIÓN: LA RECEPCIÓN DEL DISCURSO DEL PRESIDENTE RAFAEL CORREA

política. Se puede decir, sin embargo, que el presidente Correa presenta un discurso que concreta, profundiza, contextualiza e integra información, proporcionando a los ciudadanos herramientas conceptuales para pensar la política, distintas a las otorgadas tradicionalmente por los medios.

Correa reconoce explícitamente a los medios como adversarios políticos. "Hemos vencido al poder más grande del país", expresa tras la consulta popular de 2011. Esto explica el importante espacio que ha tenido la prensa en los discursos presidenciales, en cada uno de los Enlaces, y a lo largo de los años de gobierno. Pero la confrontación con los medios parece ir más allá de una mera función informativa. Si los medios se constituyen en antagónicos es porque, tal como están establecidos, constituyen una amenaza a la identidad, no solamente del gobierno, sino de un proceso democratizador en el cual sea posible construir significaciones nuevas sobre la política y lo político.

\section{Ciudadanos receptores: opiniones públicas, imágenes y representaciones}

En esta reflexión nos separamos de las teorías que definen la opinión pública a partir de atributos o cualidades esenciales (Lippmann, 1931; Dewey, 2004; Lazarsfeld, 1957; Noelle-Neumann, 1995). Tampoco la concepción dominante, fundada en la tradición liberal-funcionalista, que la piensa como una mera sumatoria de opiniones individuales recogidas a través de sondeos, satisface nuestro interés por analizar la producción de sentidos en la que se involucran los destinatarios del discurso político de Correa.

A los fines de recuperar esta producción significante, preferimos apoyarnos en reflexiones de Bourdieu, quien concibe la opinión pública como un sistema de fuerzas, tensiones y desigualdades que se traducen en

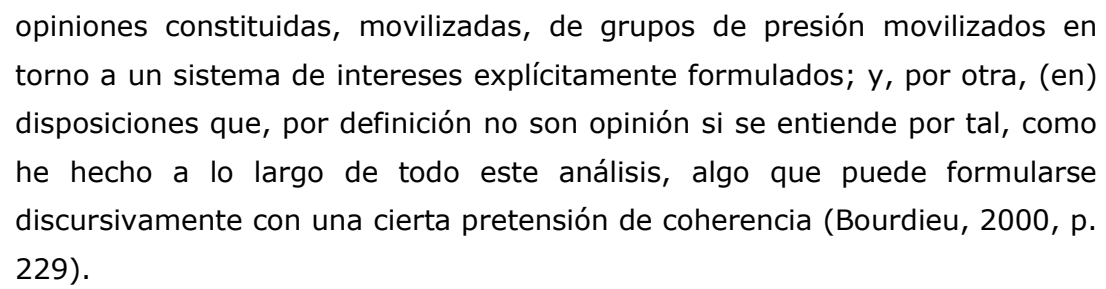

Aunque el autor no lo diga explícitamente en el trabajo citado, nos atrevemos a pensar que aquello capaz de constituir y movilizar las opiniones es, precisamente, la condición histórica - es decir, los intereses y las disposiciones - del sujeto que las enuncia. $\mathrm{Si}$, tal como hemos sugerido en las páginas precedentes, el discurso de Correa interpela al pueblo como sujeto, y exalta su identificación con éste refiriéndose siempre a la vida cotidiana de las mayorías pobres y trabajadoras, y construyendo un nosotros inclusivo al que localiza en las antípodas de los sectores privilegiados, resulta indispensable reconocer que las opiniones y posicionamientos que se evidencian en la recepción de Enlace ciudadano son expresiones de la condición histórica del pueblo al que éste se dirige. 
Estas opiniones nos muestran cómo opera en las audiencias la función de intelectual orgánico protagonizada semanalmente por Correa. En aquéllas se evidencia una profundización de la brecha entre los sectores populares y los dominantes, y se cuestiona, o se elogia, a quienes influyeron tradicionalmente en la dirección ideológica, política y cultural de la sociedad ecuatoriana, entre los que se sitúan tanto los dirigentes históricos, como miembros de la sociedad política, y los medios de comunicación. Se trata de opiniones situadas social e históricamente, que traducen tomas de posición y subjetividades políticas muy concretas. Las pensamos, por ello, como expresiones acabadas de ese sistema de fuerzas, tensiones y desigualdades al que Bourdieu denominó opinión pública.

Lo que nos interesa destacar aquí es la condición de marginalidad en la cual se producen y circulan las opiniones que construyen los ciudadanos comunes con respecto a los dispositivos y productos de comunicación política que se ponen en marcha desde los aparatos gubernamentales y electorales. Las valoraciones, argumentos y modos expresivos de los receptores suelen quedar por fuera de las encuestas, herramientas privilegiadas de los estudios de opinión pública en clave liberal. Consideramos, con Fraser, que esto no ocurre por casualidad:

En sociedades estratificadas, los grupos sociales que tienen diferentes cuotas de poder tienden a desarrollar estilos culturales desigualmente valorados. El resultado es el desarrollo de poderosas presiones informales que marginan las contribuciones de los miembros de los grupos subordinados, tanto en los contextos de la vida cotidiana como en las esferas públicas oficiales (Fraser, 1997, p. 110-111).

Por ello este análisis de la recepción de la comunicación política del gobierno de Rafael Correa es un esfuerzo por conectarnos, por la vía de las opiniones recogidas en grupos de discusión, con los sentidos y significados que nuestros interlocutores, ciudadanos comunes, construyen en su vida diaria, a propósito del país, el gobierno de turno, las formas deseables de organización de su sociedad y de rol que juegan en ella los medios de comunicación.

Las expresiones de nuestros entrevistados indican que la comunicación política del gobierno y del Presidente Correa parece aprovechar la dicotomización del campo social, tratando de poner en evidencia una escisión ya existente: la que marginaliza a ciertos sectores en favor de otros. El Presidente habría provisto a los destinatarios de sus mensajes de símbolos con los cuales hacer frente a las relaciones de dominación, otorgando palabras a los sectores populares, para nombrar dichas relaciones desiguales. Así lo expresan algunos de nuestros entrevistados:

Otra cosa que me parece interesante es también que a ciertos grupos subalternos les provee una serie de significantes. Yo nunca he estado de acuerdo en que se diga que él vino a dividir las aguas, no, yo creo que ya había un contexto donde existía ese enfrentamiento donde todo el mundo 
PUEBLO, POLÍTICA Y COMUNICACIÓN: LA RECEPCIÓN DEL DISCURSO DEL PRESIDENTE RAFAEL CORREA

"choleaba"8 y él, en cambio, les dice "pelucón". Provee una serie de significantes que la gente que tal vez no tenía una apropiación, porque la palabra es una forma de poder, entonces él me dio una serie de significantes con los que yo puedo devolver esas cosas a la gente (participante 9, hombre, educación superior, trabajador calificado, GF2, Guayaquil).

Primero [se confronta] con el sector... me gusta decir las cosas claritas, a los oligarcas, constituido por los ricos: exportadores e importadores, banqueros, dueños de periódicos, dueños de las estaciones de televisión, políticos que medraron... de todos ellos. Ese es el sector que principalmente se enfrenta al presidente Correa (participante 4, mujer, educación media, trabajadora calificada, GF1, Cuenca).

\section{Representaciones sobre Enlaces Ciudadanos}

Algunos de nuestros interlocutores tienen una evaluación positiva de los procesos de comunicación del gobierno, y de sus contenidos y las modalidades que asume la producción de dicha información. Otros entrevistados afirman haberse fortalecido en sus capacidades argumentativas, por el hecho de recibir información política desde el mismo gobierno, y de haber podido incorporar dicha información:

Magníficas [las sabatinas ${ }^{9}$, uno se informa muy bien, uno está en la posibilidad de rebatir, a nivel de uno, todas las afirmaciones que hay, falsas, por desconocimiento o por mala fe (participante 4, mujer, educación media, trabajadora calificada, GF1 Cuenca).

Como ya hemos señalado, a través de distintos recursos, como spots, pequeños documentales y reportes de corte periodístico que funcionan como réplicas o desmentidos, en Enlaces Ciudadanos se presentan imágenes e ideas específicas vinculadas al conflicto con los medios y otros sectores de poder. A este respecto, y a pesar de que existen opiniones encontradas entre nuestros entrevistados, estas réplicas a los medios se conciben como una necesidad, porque ponen en entredicho su credibilidad, antes poco cuestionada, y porque además instruyen a la ciudadanía de lo que ocurre en "la realidad":

Es, sí, importante y necesario hacer las réplicas y decir lo que no está sucediendo desde la otra perspectiva. Porque cuando recibíamos solo la noticia del noticiero, del canal de TV, de lo que venía en prensa, nosotros dábamos por sentado que es eso, y sí nos ayuda como ciudadanos poder decir, si él está diciendo y dando su postura, por lo menos voy a dudar de lo que se está viendo y lo que está pasando atrás (participante 10, hombre, educación superior, trabajador calificado, GF1, Guayaquil).

\footnotetext{
8 "Cholear", es decir, llamar cholo a alguien, significa aludir despectivamente a su condición de mestizo.
}

9 El Enlace ciudadano también es conocido como "sabatina", debido a que se emite todos los sábados. 
El trabajo que hace el Presidente de semana a semana de informar va introduciéndose en el corazón de la gente, en consecuencia, la reacción nuestra es ir despreciando los medios de información que no son veraces, que tienen, a mi modo de ver y al de una gran mayoría del pueblo ecuatoriano... y de ahí el resultado de las elecciones (participante 4, mujer, educación básica, trabajadora no calificada, GF2, Cuenca).

A pesar de que el proceso comunicativo del gobierno con la ciudadanía pueda parecer a algunos, de una dimensión excesiva, los Enlaces son valorados por haber tendido un lazo de interlocución con el pueblo, y porque a través de ellos se transmite un esfuerzo por generar comprensión acerca de las acciones de gobierno, y por mostrar "cómo funcionan las cosas":

Y tiene una facilidad de explicar Correa, que le hace entender (...). Como ustedes dicen, yo al menos, no entiendo a veces de los contratos, cosas que no, no puedo entender, pero Correa más o menos nos explica de una manera que sí se le entiende (...) Y yo digo, sí vamos a salir adelante y eso nos da ánimo, sí vamos a poder salir, eso nos ha hecho que respaldemos a Correa (participante 4, mujer, educación media, trabajadora calificada, GF1, Cuenca).

Otra cosa interesante de él [Correa] es su forma de explicar, de manera pedagógica en las sabatinas y uno entiende cosas de economía o cuestiones sociales. Es muy claro en explicar. Antes los mandatarios decían "ah, el pueblo es bruto" (participante 9, hombre, educación superior, trabajador calificado, GF2, Guayaquil).

Desde la visión de los entrevistados, Enlaces Ciudadanos constituyen un modo de construir capital político para el gobierno, y de trazar la agenda política del país durante la semana. Asimismo, los mensajes presidenciales de cada sábado habrían dado una mayor visibilidad nacional a provincias, localidades y pueblos que no eran conocidos ni tomados en cuenta por gobiernos anteriores, otorgando notoriedad a las cuestiones locales. El presidente Correa va cada semana a una ciudad distinta a producir su discurso, acompañado de los ministros y colaboradores más cercanos, y hace referencia a las autoridades y a las figuras políticas y sociales destacadas del lugar. Menciona y elogia las características culturales de los pueblos, analiza los problemas de la localidad, anuncia obras, y planifica intervenciones.

Hizo una sabatina desde Añangu, una comunidad kichwa, allá cerca de Yasuní. La gente no se la creía. Está feliz, y es eso, o sea, es algo así como dar esperanza a la gente (participante 2, mujer, educación básica, trabajadora no calificada, GF2, Quito).

No hay que olvidar que Correa es un hombre que gana porque va a todos los pueblos, las sabatinas se dan en cada lugar del país, no solamente va a hablar, 
sino que rinde cuentas con todos sus funcionarios sobre qué obras se hacen en cada lugar, qué intervención tiene el Estado (participante 5, hombre, educación superior, trabajador calificado, GF2, Guayaquil).

Una dimensión que aparece de manera un tanto sorprendente es la importancia que los ciudadanos confieren al aspecto del "entretenimiento", en la valoración que realizan respecto de los mensajes presidenciales. De modo coherente, dicha dimensión remite al formato de la comunicación de masas y al lenguaje de los medios, más allá de los contenidos y de los significados transmitidos. Las modalidades discursivas empleadas y el uso de recursos como la exageración, la ironía, el humor, confieren a los mensajes presidenciales lo que los ciudadanos Ilaman "elementos llamativos", que resultan estratégicos para atraer la atención, a través de y a pesar de las estructuras mediáticas.

Creo que pasa por buscarle elementos, en términos estratégicos... que produzcan un lenguaje llamativo. Esto a lo que yo llamo divertido, si es así... porque caso contrario nadie oyera (sic), también. Es como cuando el Vicepresidente da un Enlace, no sé si ustedes lo han escuchado, nos podrá caer súper bien, pero es aburridísimo, o sea, no es lo mismo. Con el otro [Correa] te ríes a cada rato, hasta por las payasadas que habla, yo que sé. 0 sea, realmente es divertido, es hasta como para desconectarte del mundo y reírte un rato; bueno, a momentos (participante 6 , hombre, educación superior, trabajador calificado, GF2, Quito).

\section{Medios y libertad de expresión}

El discurso presidencial también ha puesto de relieve las contradicciones generadas respecto a la libertad de expresión en el conflicto con los medios de comunicación, y la misma confianza ciudadana respecto de la información y del poder de los medios.

Hemos estado alienados en este sopor mediático no cuestionado ni autocuestionado y nosotros como ciudadanos, pasivamente, consumíamos lo que medianamente publicaban (participante 5, hombre, educación superior, trabajador calificado, GF2, Guayaquil).

El debate sobre la libertad de expresión pondría de manifiesto la desigualdad en el acceso a la palabra pública existente entre los propietarios de medios y periodistas, y los ciudadanos comunes. En este contexto, las regulaciones gubernamentales que intentan limitar el poder mediático, y reivindicar el carácter de la comunicación como bien público, se representan como justas.

Evidentemente, los medios han estado vetados para la gran mayoría de gente.

Es decir, los amplificadores de posiciones políticas o económicas. Entonces, esto de la libertad de expresión, en relación con los grandes medios, es una 
falacia, no es que teníamos libertad de expresión (participante 6, hombre, educación superior, trabajador calificado, GF2, Quito).

La libertad de expresión tiene diversas definiciones, que difieren según las adscripciones ideológicas y teóricas de quien hable. Una definición de libertad de expresión comúnmente conocida es la negativa, la que consiste en no limitar lo que los individuos desean expresar. Para los ciudadanos consultados, la libertad de expresión positiva supone priorizar la información que responda a necesidades y demandas sociales. La libertad de expresión es definida por nuestros interlocutores como una cuestión general, colectiva, que no se reduce necesariamente a la prensa o a alguna institución en particular.

Libertad de expresión es poder nosotros decir lo que sentimos, lo que pensamos, y no estar a expensas de que algo nos pueda pasar, de que nos van a reprimir, las consecuencias... Es decir, lo que uno piensa obviamente de una manera responsable y educada (participante 2, mujer, educación superior, empresaria, GF2, Cuenca).

La dignidad de las personas es otra de las condiciones de la libertad de expresarse:

Que libremente se expresen (...) en una forma racional, como tiene que ser, sin ofender la dignidad de la persona (participante 2, mujer, educación superior, empresaria, GF2, Cuenca).

La libertad de expresión es representada por nuestros interlocutores como necesaria, pero no como absoluta. Debería, según dicen, estar sujeta a que lo que se dice sea comprobable, veraz y respetuoso de la imagen de las personas a las que hace referencia:

Yo creo en que todos tenemos derecho a tener nuestra opinión respecto de cualquier cosa. Pero, yo creo que eso no es pretexto para decir cualquier cosa, a quien sea. Yo creo que eso sí tiene que ver mucho con la responsabilidad de, y la postura de cada uno, yo coincido contigo. No puedo, yo quiero pensar en un país en donde puedo expresar libremente mi opinión. Pero, no es que la voy a expresar indiscriminadamente a quien sea, y no hacerme responsable de esto que yo estoy diciendo (participante 1 , hombre, educación media, trabajador calificado, GF2, Quito).

\section{Complejidades de la participación política}

En los grupos de discusión, ante la pregunta a los participantes sobre si se sienten más partícipes en la vida política del país, se producen respuestas complejas. Por un lado, reconocen que existe un mayor entusiasmo por la política, y una mayor visibilidad de grupos, movimientos sociales, minorías sociales.

Yo pienso que sí, por eso aparecen tantos movimientos, tantas organizaciones políticas, tantos partidos. (...) Sí se han fomentado diferentes espacios desde 
PUEBLO, POLÍTICA Y COMUNICACIÓN: LA RECEPCIÓN DEL DISCURSO DEL PRESIDENTE RAFAEL CORREA

diferentes puntos de vista donde la gente sí puede participar (participante 1, hombre, educación superior, trabajador calificado, GF2, Cuenca).

Sí hay, el mismo hecho de que tenemos personas de todas las ciudades en el gobierno, es que están participando (participante 1, hombre, educación superior, trabajador calificado, GF2, Cuenca).

Sí hay espacios, me parece, para los jóvenes. Sí debe haber porque, si no, estaríamos hablando de comunismo (participante 3, mujer, educación media, trabajadora calificada, GF2, Cuenca)

Para otros, el hecho de haber participado en procesos como la consulta popular, para modificar la Constitución, o el escuchar las sabatinas constituye un modo de disciplinamiento del gobierno para conducir la participación y el involucramiento de la sociedad:

Creo que hay más involucramiento, sí. Por un mismo tema de participación; y habernos disciplinado en ser más partícipes. Entonces, hasta antes de Correa, acordémonos, estábamos acostumbrados cada tres meses a botar un Presidente, y se acabó, independientemente de qué es lo que haya hecho, o dejado de hacer. Más bien creo que uno de los grandes aciertos de este gobierno, es haber, o estar constantemente en este ejercicio de disciplinar a la ciudadanía en participar. O sea, el hecho de la Constitución es un gran acierto, desde mi punto de vista, es una Constitución que nos ha llevado a mirar otras cosas. Entonces, que se aplique adecuadamente es muy diferente. Pero, fue un ejercicio de participación ciudadana. $Y$ eso nos lleva a involucrarnos. La misma cuestión de las cadenas sabatinas, no es que me guste todos los sábados, pero, yo creo que es un ejercicio necesario para poder ser partícipes. Entonces, yo creo que sí. Sí hay un involucramiento. Hay un involucramiento mayor (participante 1, hombre, educación superior, trabajador calificado, GF1, Quito).

Por otro lado, se afirma que la participación no ha trascendido el ámbito de lo enunciativo; en este sentido se hace alusión a la participación directa, aquella que ha sido promovida como parte de los procesos de planificación en el discurso de las políticas públicas:

Yo, en lo personal, no. A pesar que... existe una función de la participación ciudadana y todo, pero yo creo que no existe de verdad una participación. En los gobiernos municipales, provinciales, existe esto de la silla vacía, donde el ciudadano va y puede conversar con la autoridad, pero hasta donde yo sé, dicen que eso es, únicamente se ha quedado en escrito, en teoría, no existe una verdadera participación de los ciudadanos en la vida política (participante 7, hombre, educación media, trabajador calificado, GF1, Cuenca). 


\section{Autoestima y orgullo nacional}

De acuerdo a lo discutido con nuestros interlocutores, el Presidente pondría de relieve el valor de la soberanía, de lo nacional y de lo propio en su discurso. De ese modo, estaría contribuyendo a reforzar la autoestima y a hacer que los ecuatorianos se sientan orgullosos de la tierra en la que nacieron. Se destaca, además, la labor del gobernante en dar a conocer el país en el extranjero:

Hay otro elemento que también es recurrente, es este tema de construir una suerte de autoestima de orgullo nacional, que tiene que ver con la soberanía, es un tema recurrente, que a mí me parece positivo (...). Pero, es esa lógica de adhesión, de identidad ecuatoriana, de orgullo, de eso, eso es recurrente. Es otro de los valores que está en su discurso de manera permanente (participante 6, hombre, educación superior, trabajador calificado, GF2, Quito).

Porque más que todo ya somos conocidos. A pesar que, más antes, de aquí no tenían ese conocimiento, o mejor dicho de afuera no tenían el conocimiento de lo que aquí Ecuador era, de lo que el país producía y lo que Ecuador es. En cambio, ahora, que con este Presidente que ahora tenemos, él habla, va por todo lado. Él habla de todo lo que tiene Ecuador. Entonces ya somos conocidos por todo el mundo, entonces ya no somos el país pequeño que lo veían como una manchita nomás, ahí en el mapa. Ahora el país pequeño que era, es grande de corazón. Y grande de todo mismo (participante 3, mujer, educación media, trabajadora calificada, GF1, Quito).

Otro rasgo importante que notan los entrevistados en Enlaces Ciudadanos es la percepción de que se hace explicito, de manera permanente, un sentido de Patria, que no consiste solamente en la enunciación de la palabra, sino, sobre todo, en la construcción de una identificación con el país que se produce a través del trabajo y de la rendición de cuentas sobre lo realizado día a día:

Sí hay algo positivo que yo puedo rescatar de esta práctica de las sabatinas. Para mí son agotadoras las sabatinas. No son divertidas para mí. Me parecen interesantes, pero, creo que, si hay algo positivo que marca las sabatinas, es esta cuestión de "Construir Patria", "Patria todos los días". Patria se hace todos los días. No se hace patria cantando el himno nacional los lunes, ni, ¿qué sé yo?, de todo los que nos enseñaron cuando había cívica ${ }^{10}$. [risas] Pero yo creo que sí es esto, o sea, al presentar su agenda, muestra su plan, o sea que no es que está desocupado. Y que también, para mí, sí es hacer Patria todos los días. Porque es estar pendiente de todo lo que hay que hacer. Si algo positivo

\footnotetext{
10 Nuestro interlocutor se refiere a la asignatura denominada "Educación Cívica" que se impartía en las
} escuelas primaria y secundaria. 
PUEBLO, POLÍTICA Y COMUNICACIÓN: LA RECEPCIÓN DEL DISCURSO DEL PRESIDENTE RAFAEL CORREA

yo rescato de las sabatinas es eso (participante 1 , hombre, educación superior, trabajador calificado, GF1, Quito).

\section{Reflexiones finales}

El presente artículo buscó aportar a la discusión en torno a un aspecto poco evaluado en la investigación de la comunicación política: la recepción, entendida como proceso activo de construcción de sentidos por parte de las audiencias. Los debates mantenidos con ciudadanos ecuatorianos de distintos sectores socioeconómicos y geográficos, a propósito de la discursividad política de su gobierno, nos muestran que es posible - y necesario - ir más allá del análisis de los "efectos cognitivos", basados en la consonancia o disonancia de los mensajes publicitarios y propagandísticos con la información que los electores ya han adquirido y procesado (Bouza, 1998), y avanzar hacia el estudio de la producción de identidades y subjetividades políticas.

Desde esta reducción de la comunicación política a la transmisión, exitosa o fracasada, de datos y de información, se suele pasar por alto al menos tres cuestiones que consideramos fundamentales al momento de pensar el papel de los receptores y destinatarios. En primer término, su capacidad de interpretar, re-significar y tomar posición frente a los dispositivos y productos de la comunicación política. En segundo lugar, las condiciones estructurales en las cuales se desarrollan estos procesos de recepción e interpretación. $Y$, finalmente, los conflictos, disputas y consensos que hacen posible la construcción y la movilización de las identidades en los procesos de comunicación política.

Respecto de la primera cuestión, el artículo permitió poner de manifiesto no solamente dicha capacidad social de re-significar y posicionarse frente al discurso político, sino también de enunciar el reconocimiento de una valoración de la propia condición de receptores por parte de la política - lo que ubica a los mismos en un lugar de ciudadanos - y a la vez de interpretarlo críticamente. Esto ha sido posible, con distintos grados de consenso o de valor crítico, desde las diversas posiciones y condiciones de los sujetos abordados en este artículo, lo cual nos remite a la segunda cuestión. Tal vez el rasgo común de este abordaje que se homologa, en algún sentido al de la acción política que hemos analizado, es el del haber dado voz a quienes no tienen voz.

La tercera cuestión trae a luz las conflictividades y disputas que la comunicación política ha logrado poner al descubierto, y que habían estado silenciadas en el campo político y social ecuatoriano. Esto es, dominaciones y privilegios, por un lado, y opresiones y exclusiones, por el otro. Desigualdades que se expresan en el ámbito de la comunicación, que es también el lugar donde se concentran capitales económicos y culturales que determinan participaciones diferenciadas para los diversos sujetos.

El presente artículo procuró incorporar estos elementos analíticos a unos procesos y unas prácticas caracterizadas por su diversidad y complejidad. Se trata de una mirada preliminar, construida desde un estudio de caso, desde la cual se espera haber aportado a 
la reflexión sobre las limitaciones y posibilidades de la comunicación política en otros países latinoamericanos.

Conforme lo sostenido al inicio, el discurso del presidente Rafael Correa parece haber promovido, en las audiencias, la generación de una multiplicidad de representaciones que aluden a cambios políticos, valores y horizontes normativos, así como a nuevas herramientas significantes para pensar la política, el gobierno, la relación con los medios, y el país. Como efecto de los procesos de comunicación política desarrollados por el gobierno ecuatoriano, con Correa como su principal enunciador, se reconoce una mayor politización de la sociedad, en varios sentidos. Según nuestros entrevistados, existe un mayor entusiasmo por la política, un interés forjado a partir de la comunicación intensa y de la información permanente. La participación adquiere aquí significados diversos, se participa como audiencias, se participa como votantes. La política, convertida en comunicación, es vista como una entidad o un campo discursivo más presente en la vida de los ecuatorianos que en cualquier otro momento histórico.

A través de la modificación de la Constitución y el llamado a consultas populares, el gobierno habría promovido formas de participación y de involucramiento en la política, reconocidas y valoradas por los ciudadanos comunes y corrientes. No obstante, subsistirían limitaciones en las formas concretas de participación, ésas que buscan, por ejemplo, ejercer formas más idealizadas que practicadas de un mayor activismo ciudadano en procesos de rendición de cuentas de los gobiernos. La "verdadera" participación, en este sentido, parece, en los hechos, no haber superado lo meramente declarativo. Los antagonismos y adhesiones que concitan Correa y su gobierno, además de haber animado a participar a muchos, también habrían inmovilizado a ciertos actores, anulando la posibilidad del disenso.

Por otro lado, aún con la diversidad de posiciones y de puntos de vista de los entrevistados, nos ha llamado la atención la convergencia - independientemente de las afinidades, simpatías o distanciamientos de los entrevistados con el gobierno - en el reconocimiento de una caída de los medios de comunicación como proveedores de información política acertada, y sobre todo veraz. Se estaría modificando el lugar social de los medios en la producción de la verdad, y esto ha sido un efecto - reconocido por todos los informantes - del discurso confrontativo del presidente Correa frente a la prensa, y de su capacidad de instruir a la sociedad y de generar vínculos pedagógicos y políticos con los ciudadanos comunes, a través de explicaciones sobre la política pública, la acción del gobierno y el papel del Estado, que ni los políticos ni los medios fueron capaces de proporcionar. Esto, al mismo tiempo que genera identificaciones, reafirma el reconocimiento de que el pueblo es sujeto de un saber posible, frente a la descalificación de los otrora gobernantes.

Asimismo, y más allá de las críticas que se planteen sobre la gestión y el estilo del gobierno de Correa, la comunicación política del mismo es destacada, ya sea por sus efectos sobre los ciudadanos, por sus capacidades de construir una identidad política particular, o por sus posibilidades de confrontar con quienes había gozado de prerrogativas 
y privilegios históricos en el país. El discurso presidencial, al mismo tiempo que subraya los antagonismos, con la identificación continua de enemigos políticos identificados con los sectores tradicionalmente poderosos, alimenta e integra a la confrontación otras dimensiones, que son del orden de la identidad, del reconocimiento colectivo, de la construcción de un nosotros, mostrando, a la vez y ante todo, un lado afectivo y humano que no prescinde del humor, de la exageración, de los lugares comunes para comunicarse con los gobernados.

Todo ello construye empatía con los ciudadanos, aun cuando racionalmente los estilos y las decisiones políticas no sean del todo compartidos por ellos. Produce, además, una valoración del discurso político como más cercano a lo cotidiano, que puede producir risa y hasta "desconexión del mundo". Es decir, una política que genera placer y no necesariamente preocupación o indiferencia. Con los procesos de información y comunicación política que el gobierno del presidente Correa ha instaurado, se estarían conformando nuevas subjetividades sociales y políticas: sujetos informados y formados en conceptos, ideas y categorías más o menos centrales en la vida política.

Sin intentar disminuir la importancia de otros procesos de formación colectiva e individual sobre las actitudes políticas, es preciso reconocer, con nuestros entrevistados, que el proceso de comunicación del gobierno ha generado significaciones políticas y de convivencia social antes no consideradas en el lenguaje cotidiano. Nociones y significantes como derechos, autoestima, dignidad, ecuatorianidad y esperanza, parecen desplegarse y generar nuevos significados, más cercanos y accesibles a las subjetividades populares, que en tiempos en que las instituciones y partidos políticos las produjeron administrativa o simbólicamente. Un nuevo sentido de la identidad basada en la pertenencia a una nación, antes postergada, constituye un elemento más en este proceso de constitución.

La participación de los ciudadanos en la vida política del país se percibe, así, como la posibilidad de haber identificado, en el discurso del mandatario, aquello que era parte de un deseo no explicitado y posiblemente no consciente del pueblo ecuatoriano. A través del mismo, los ciudadanos parecen haber descubierto sus propios deseos o ideales de vida colectiva.

Estos ideales, movilización de afectos, nuevas significaciones y valores políticos podrían estar configurando una nueva hegemonía, o al menos, según Gramsci, un nuevo ciclo histórico en la vida política del Ecuador.

Mauro Cerbino - Profesor titular principal, Departamento de Estudios Internacionales y Comunicación, Flacso Ecuador. E-mail: <mcerbino@flacso.edu.ec>.

Marcia Maluf - Doctoranda, Universidad Nacional de San Martín, Argentina.

E-mail: <mmaluf@flacso.edu.ec>.

Isabel Ramos - Profesora titular principal, Departamento de Estudios Internacionales y Comunicación, Flacso Ecuador. E-mail: <iramos@flacso.edu.ec>. 


\section{Referencias bibliográficas}

AngenOt, M. El discurso social: los límites históricos de lo pensable y lo decible. Buenos Aires: Siglo XXI, 2010.

BARTRA, R. "Populismo y democracia en América Latina". Letras Libres, no 112, abr. 2008. Disponible en: <http://www.letraslibres.com/mexico/populismo-y-democracia-en-america-latina>. Acceso en: 10 mar. 2017.

Bourdieu, P. La opinión pública no existe. In: Bourdieu, P. Cuestiones de sociología. Madrid: Akal, p. 220-232, 2000.

BouzA, F. "Comunicación política: encuestas, agendas y procesos cognitivos electorales". Praxis Sociológica, Toledo, n 3, p. 49-58, 1998.

CERBino, M., et al. The dispute over public opinion: the mediatization of politics and the politicization of the media in Ecuador. In: MARTENS, C.; VivARES, E.; MCCHESNEY, R. (eds.). The international political economy of communication, media and power in South America. Londres: Palgrave Macmillan, p. 65-83, 2014.

Charaudeau, P. Pathos e discurso político. In: Machado, I.; Menezes, W.; Mendez, E. (coords.). As emoções no discurso. Rio de Janeiro: Lucerna, p. 240-251, 2007.

. La argumentación persuasiva: el ejemplo del discurso político. In: SHIRo, M., et al. Haciendo discurso: homenaje a Adriana Bolívar. Caracas: Facultad de Humanidades y Educación, Universidad Central de Venezuela, 2009.

. "Las emociones como efectos de discurso". Versión, México, n² 26, p. 97-118, jun. 2011.

Chavero, P.; Cerbino, M. "Más allá de la rendición de cuentas: Ios Enlaces Ciudadanos como escenario de disputa político-mediática en Ecuador". In: Anales del VI Congreso Internacional GIGAPP "Nuevos caminos para la gobernanza en Iberoamérica", Madrid, 2015.

De LA TORRE, C. "El tecnopopulismo de Rafael Correa ¿Es compatible el carisma con la tecnocracia?". Latin American Research Review, Pittsburgh, vol. 48, no 1, p. 24-43, 2013.

DEWEY, J. La opinión pública y sus problemas. Madrid: Morata, 2004.

FRASER, N. Pensando de nuevo la opinión pública: una contribución a la crítica de las democracias existentes. In: FRASER, N. Iustitia interrupta. Reflexiones críticas desde la posición postsocialista. Bogotá: Siglo del Hombre Editores, Universidad de los Andes, p. 95-133, 1997.

GramsCI, A. Antología. Buenos Aires: Siglo XXI, 2004.

LACLAU, E. La razón populista. Buenos Aires: Fondo de Cultura Económica, 2005.

LAZARsfeld, P. "Public opinion and the classical tradition". The Public Opinion Quarterly, Princeton, vol. 21, no 1 , p. 39-53, 1957.

Lippmann, W. "The press and the public opinion". Political Science Quarterly, Nueva York, vol. 46, no 2, p. 161-170, 1931.

Noelle-NeumanN, E. La espiral del silencio: opinión pública nuestra piel social. Buenos Aires: Paidós, 1995.

Novaro, M. "Los populismos latinoamericanos transfigurados". Nueva Sociedad, Buenos Aires, $\mathrm{n}^{\circ}$ 144, p. 90-103, 1996. 
PUEBLO, POLÍTICA Y COMUNICACIÓN: LA RECEPCIÓN DEL DISCURSO DEL PRESIDENTE RAFAEL CORREA

Orozco GómEz, G. "Los estudios de recepción: de un modo de investigar, a una moda, y de ahí a mucho modos". Intexto, vol. 2, n 9, p. 1-13, jul.-dic. 2003.

PALACIO, E. "No a las mentiras". El Universo, 6 feb. 2011. Disponible en:

<http://www.eluniverso.com/2011/02/06/1/1363/mentiras.html>. Acceso en: 15 mayo 2016.

PARAmio, L. "Giro a la izquierda y regreso del populismo". Nueva Sociedad, n 205, p. 62-74, 2006.

Romano, A. "Humor y discurso político". PhaoS: Revista de Estudos Clássicos, n 1, p. 59-169, 2001.

SÁnChez PARgA, J. "La democracia caudillista en Ecuador". Araucaria: Revista Iberoamericana de Filosofía, Política y Humanidades, n²2, p. 186-214, 2009.

Verón, E. La palabra adversativa: observaciones sobre la enunciación política. In: Verón, E., et al. El discurso político: lenguajes y acontecimientos. Buenos Aires: Hachette, 1987.

\section{Documentos consultados}

"La vía del Ecuador". Entrevista a Rafael Correa, New Left Review, no 77, p. 81-102 [online]. Disponible en: <newleftreview.es/article/download_pdf?language=es\&id=2986>. Acceso en: 12 abr. 2016.

Enlaces 206, 208, 215, 217 e 218. Enlaces Ciudadanos. Presidencia del Ecuador. Disponible en: <http://www.enlaceciudadano.gob.ec/blog>. Acceso en: 3 jul. 2017.

\section{Resumen}

Pueblo, política y comunicación: la recepción del discurso del presidente Rafael Correa

Este artículo analiza el dispositivo de comunicación política denominado Enlace Ciudadano, que conduce semanalmente el presidente ecuatoriano Rafael Correa y es transmitido por radio y televisión, con la finalidad de caracterizar los sentidos que construyen los ciudadanos en torno a la acción de gobierno, las relaciones de Correa con los medios, sus formas de comunicación política, sus propuestas y las relaciones con otros actores políticos afines y opositores. A través de un estudio cualitativo que combinó el análisis del discurso y los estudios de recepción, se comprobó que el discurso presidencial ha promovido en las audiencias la generación de nuevos sentidos y significados para pensar la política y la relación de los ciudadanos con el Estado y los medios de comunicación. El artículo muestra diversas racionalidades e interpretaciones de ciudadanos que son al mismo tiempo destinatarios y receptores activos del discurso político. Estos resultados aportan algunas claves sobre los procesos político-culturales que están en la base del arraigo que presidentes denominados peyorativamente "populistas", como Rafael Correa, han logrado en la población de sus países, en particular entre los sectores económica y socialmente más desfavorecidos. Ellos abrevan en la constitución de subjetividades que reconocen el valor de la identidad, los derechos, la autoestima, y la necesidad de relaciones menos desiguales, dejando también una puerta abierta a la diferencia y a la confrontación política. El artículo contribuye además a la discusión alrededor del significado político del sentido común en la configuración de la hegemonía en el contexto contemporáneo caracterizado por la mediatización de la política.

Palabras clave: comunicación política; estudios de recepción; discurso político; opinión pública; Ecuador 


\section{Resumo}

Povo, política e comunicação: a recepção do discurso do presidente Rafael Correa

Este artigo analisa o dispositivo de comunicação política denominado Enlace Ciudadano conduzido semanalmente pelo presidente equatoriano Rafael Correa e transmitido por rádio e televisão, com a finalidade de caracterizar os sentidos de construção dos cidadãos em torno das ações do governo, suas relações com a mídia, as formas de comunicação política, suas propostas e as relações com outros atuantes políticos afins e opositores. Através de um estudo qualitativo que combinou a análise do discurso e estudos de recepção, comprovou-se que o discurso presidencial promoveu nas audiências a geração de novos julgamentos e significados ao pensar na política e na relação dos cidadãos com o Estado e os meios de comunicação. O artigo mostra as diversas racionalidades e interpretações de cidadãos que são ao mesmo tempo destinatários e receptores ativos do discurso político. Esses resultados abordam alguns pontos-chave dos processos político-culturais que estão na base da manutenção que os presidentes denominados pejorativamente de "populistas", como Rafael Correa, conseguiram na população de seus países, em particular entre os setores econômico e social mais desfavorecidos. Eles contribuem para a formação de subjetividades que reconhecem o valor de identidade, direitos, autoestima, e a necessidade de relações menos desiguais, também deixando uma porta aberta para a diferença e o confronto político. Além disso, o artigo promove a discussão ao redor do significado político do sentido comum na configuração da hegemonia no contexto contemporâneo caracterizado pela midiatização da política.

Palavras-chave: comunicação política; estudos de recepção; discurso político; opinião pública; Equador

\section{Abstract}

People, politics, and communication: the reception of the discourse of president Rafael Correa

This article analyzes the political communication dispositive called Enlace Ciudadano led weekly by the president of Ecuador Rafael Correa, which is broadcasted by radio and television in order to characterize the meanings that citizens build about the government's actions, Correa's relationship with the media, his way of communicating in the political space, his proposals, and his relations with other political actors, both those aligned with and in opposition to the government. Through a qualitative study that combines discourse analysis and reception studies, the presidential discourse was found to promote the generation of new meanings and ways of thinking about politics and the relationship between citizens and the government and media. The article shows citizens' different rationalities and interpretations-citizens who are both the target and active receptors of the political discourse. The results provide some key elements about the processes that are the basis of the rootedness that presidents pejoratively called "populist," like Rafael Correa, have achieved among their countries' population, particularly in the economically and socially disadvantaged sectors. These elements contribute to the constitution of subjectivities that recognize the value of identity, rights, self-esteem, and the necessity of more equal relationships, while also leaving a door open to different ways of thinking and political confrontation. Moreover, the article contributes to the discussion around the political meaning of common sense in the configuration of hegemony in the contemporary context characterized by the mediatization of politics.

Keywords: political communication; reception studies; political discourse; public opinion; Ecuador

\section{Résumé}

Peuple, politique et communication: la réception du discours du président Rafael Correa

Cet article analyse le dispositif de communication politique nommé Lien Citoyen, que le président équatorien Rafael Correa présente chaque semaine, et qui est transmis à la radio et à la télévision, dans le but de caractériser les sens que les citoyens construisent au sujet de l'action du gouvernement; les relations de Correa avec les médias, ses modèles de communication politique, ses propositions et ses relations avec d'autres acteurs politiques, alliés et adversaires. À travers une étude qualitative qui 
a combiné l'analyse du discours et les études de réception, on a démontré que le discours présidentiel a promu, auprès de son auditoire, la génération de nouveaux sens et significations pour penser la politique et la relation entre les citoyens, l'État et les médias. L'article montre les diverses rationalités et les interprétations de citoyens qui sont en même temps les destinataires et les récepteurs actifs du discours politique. Ces résultats apportent quelques clés sur les processus politico-culturels qui sont à la base de l'enracinement que les présidents dénommés "populistes", comme Rafael Correa, ont obtenu dans la population de ses pays, en particulier entre les secteurs économiques et socialement plus défavorisés. Ils contribuent à la constitution de subjectivités qui prennent en compte la valeur de l'identité, les droits, l'estime de soi, et la nécessité de relations moins inégales, laissant la porte ouverte à la différence et à la confrontation politique. L'article contribue, de plus, à la discussion autour du signifié politique du sens commun dans la configuration de l'hégémonie, dans un contexte contemporain caractérisé par la médiatisation de la politique.

Mots clés: communication politique; études de réception; discours politique; opinion publique; Équateur

Artículo sometido para publicación el 3 de octubre de 2016.

Versión final aprobada el 8 de junio de 2017. 